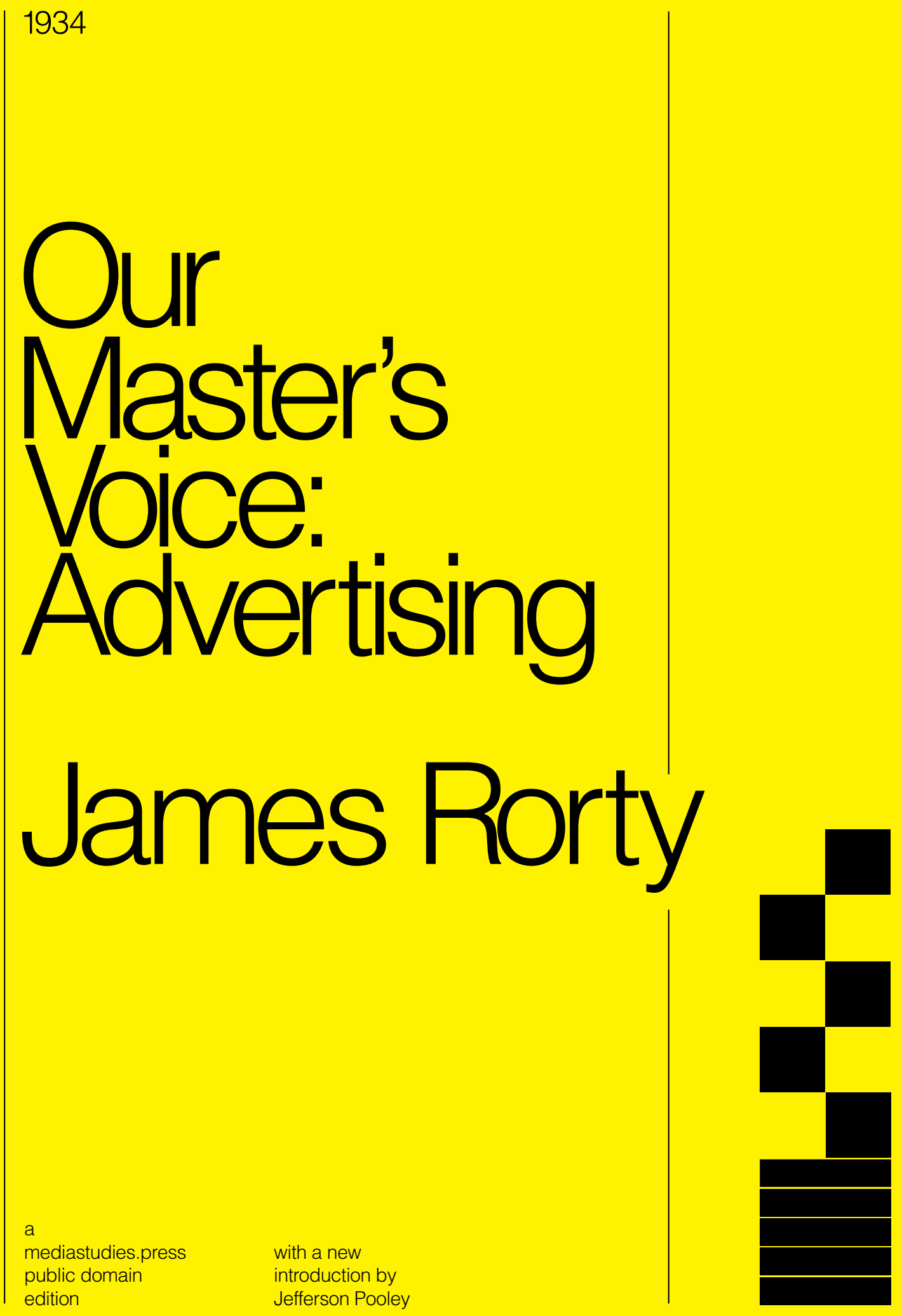




\section{James Rorty}

OUR MASTER'S VOICE

ADVERTISING 
Our Master's Voice: Advertising, originally published in 1934 by the JOHN DAY COMPANY, is in the public domain.

Published by mediastudies.press in the public domain series

mediastudies.press I 414 W. Broad St., Bethlehem, PA 18018, USA

New materials are licensed under a Creative Commons Attribution-Noncommercial 4.0 (CC BY-NC 4.0)

COvER DeSIgN: Mark McGillivray

CREDIT FOR SCAN: Internet Archive, contributor Prelinger Library, 2006 upload

CREDit FOR LATeX template: Book design inspired by Edward Tufte, by The Tufte-LaTeX Developers

ISBN 978-1-951399-00-9 (print) I ISBN 978-1-951399-01-6 (ebook)

DOI $10.21428 / 3 \mathrm{f} 8575 \mathrm{cb} . d b b a 9917$

LIBRARY OF CONGRESS CONTROL NUMBER 202094177

Edition 1 published in October 2020 


\section{THE BUSINESS NOBODY KNOWS}

THE title of this chapter was chosen, not so much to parody the title of Mr. Bruce Barton's widely-read volume of New Testament exegesis, ${ }^{1}$ as to suggest that, in the lack of serious critical study, we really know very little about advertising: how the phenomenon happened to achieve its uniquely huge and grotesque dimensions in America; how it has affected our individual and social psychology as a people; what its rôle is likely to be in the present rapidly changing pattern of social and economic forces.

The advertising business is quite literally the business nobody knows; nobody, including, or perhaps more especially, advertising men. As evidence of this general ignorance, one has only to cite a few of the misapprehensions which have confused the very few contemporary economists, sociologists and publicists who have attempted to treat the subject.

Perhaps the chief of these misapprehensions is that of regarding advertising as merely the business of preparing and placing advertisements in the various advertising media: the daily and periodical press, the mails, the radio, motion picture, car cards, posters, etc. The error here is that of mistaking a function of the thing for the thing itself. It would be much more accurate to say that our daily and periodical press, plus the radio and other lesser media, are the advertising business. The commercial press is supported primarily by advertising - roughly the ratio as between advertising income and subscription and news-stand sales income averages about two to one. It is quite natural, therefore, that the publishers of newspapers and magazines should regard their enterprises as advertising businesses. As a matter of fact, every advertising man knows that they do so regard them and so conduct them. These publishers are business men, responsible to their stockholders, and their proper and necessary concern is to make a maximum of profit out of these business properties. They do this by using our major instruments of social communication, whose free and disinterested functioning is embodied in the concept of a democracy, to serve the profit interests of the advertis- doi I original pdf

${ }^{1}$ [Bruce Barton, The Man Nobody Knows (New York: Grosset \& Dunlap, 1924).] 
ers who employ and pay them. Within certain limits they give their readers and listeners the sort of editorial content which experience proves to be effective in building circulations and audiences, these to be sold in turn at so much a head to advertisers. The limits are that regardless of the readers' or listeners' true interests, nothing can be given them which seriously conflicts with the profit-interests of the advertisers, or of the vested industrial and financial powers back of these; also nothing can be given them which seriously conflicts with the use and wont, embodied in law and custom, of the competitive capitalist economy and culture.

In defining the advertising business it must be remembered also that newspapers and magazines use paper and ink: a huge bulk of materials, a ramified complex of services by printers, lithographers, photographers, etc. Radio uses other categories of materials and services-the whole art of radio was originally conceived of as a sales device to market radio transmitters and receiving sets. All these services are necessary to advertising and advertising is necessary to them. These are also the advertising business. Surely it is only by examining this business as a whole that we can expect to understand anything about it.

The second misapprehension is that invidious moral value judgments are useful in appraising the phenomena. Advertising is merely an instrument of sales promotion. Good advertising is efficient advertising-advertising which promotes a maximum of sales for a minimum of expenditure. Bad advertising is inefficient advertising, advertising which accomplishes its purpose wastefully or not at all. All advertising is obviously special pleading. Why should it be considered pertinent or useful to express surprise and indignation because special pleading, whether in a court of law, or in the public prints, is habitually disingenuous, and frequently unscrupulous and deceptive? Yet liberal social critics, economists and sociologists, have wasted much time complaining that advertising has "elevated mendacity to the status of a profession." The pressure of competition forces advertisers and the advertising agencies who serve them to become more efficient; to advertise more efficiently frequently means to advertise more mendaciously. Do these liberal critics want advertising to be less efficient? Do they want advertisers to observe standards of ethics, morals and taste which would, under our existing institutional setup, result either in depriving stockholders of dividends, or in loading still heavier costs on the consumer?

There is, of course, a third alternative, which is neither good advertising nor bad advertising, but no advertising. But that is outside the present institutional setup. It should be obvious that in the present (surplus economy) phase of American capitalism, advertising 
is an industry no less essential than steel, coal, or electric power. If one defines advertising as the total apparatus of American publishing and broadcasting, it is in fact among the twelve greatest industries in the country. It is, moreover, one of the most strategically placed industries. Realization of this fact should restrain us from loose talk about "deflating the advertising business." How would one go about organizing "public opinion" for such an enterprise when the instruments of social communication by which public opinion must be shaped and organized are themselves the advertising business?

As should be apparent from the foregoing, the writer has only a qualified interest in "reforming" advertising. Obviously it cannot be reformed without transforming the whole institutional context of our civilization. The bias of the writer is frankly in favor of such a transformation. But the immediate task in this book is one of description and analysis. Although advertising is forever in the public's eye-and in its ear too, now that we have radio-the average layman confines himself either to applauding the tricks of the ad-man, or to railing at what he considers to be more or less of a public nuisance. In neither case does he bother to understand what is being done to him, who is doing it, and why.

The typical view of an advertisement is that it is a selling presentation of a product or service, to be judged as "good" or "bad" depending upon whether the presentation is accurate or inaccurate, fair or deceptive. But to an advertising man, this seems a very shallow view of the matter.

Advertising has to do with the shaping of the economic, social, moral and ethical patterns of the community into serviceable conformity with the profit-making interests of advertisers and of the advertising business. Advertising thus becomes a body of doctrine. Veblen defined advertisements as "doctrinal memoranda," and the phrase is none the less precise because of its content of irony. It is particularly applicable to that steadily increasing proportion of advertising classified as "inter-industrial advertising": that is to say, advertising competition between industries for the consumer's dollar. What such advertising boils down to is special pleading, directed at the consumer by vested property interests, concerning the material, moral and spiritual content of the Good Life. In this special pleading the editorial contents of the daily and periodical press, and the sustaining programs of the broadcasters, are called upon to do their bit, no less manfully, though less directly than the advertising columns or the sponsor's sales talk. Such advertising, as Veblen pointed out, is a lineal descendant of the "Propaganda of the Faith." It is a less unified effort, and less efficient because of the conflicting pressure groups involved; also because of the disruptive stresses of the under- 
lying economic forces of our time. Yet it is very similar in purpose and method. ${ }^{2}$

An important point which the writer develops in detail in later chapters is that advertising is an effect resulting from the unfolding of the economic processes of modern capitalism, but becomes in turn a cause of sequential economic and social phenomena. The earlier causal chain is of course apparent. Mass production necessitated mass distribution which necessitated mass literacy, mass communication and mass advertising. But the achieved result, mass advertising, becomes in turn a generating cause of another sequence. Mass advertising perverts the integrity of the editor-reader relationship essential to the concept of a democracy. Advertising doctrine-always remembering that the separation of the editorial and advertising contents of a modern publication is for the most part formal rather than actualis a doctrine of material emulation, keeping up with the Joneses, conspicuous waste. Mass advertising plus, of course, the government mail subsidy, makes possible the five-cent price for national weeklies, the ten- to thirty-five-cent price for national monthlies. Because of this low price and because of the large appropriations for circulationpromotion made possible by advertising income, the number of mass publications and the volume of their circulation has hugely increased. These huge circulations are maintained by editorial policies dictated by the requirements of the advertisers. Such policies vary widely but have certain elements in common. Articles, fiction, verse, etc., are conceived of as "entertainment." This means that controversial subjects are avoided. The contemporary social fact is not adequately reported, interpreted, or criticized; in fact the run of commercial magazines and newspapers are extraordinarily empty of social content. On the positive side, their content, whether fiction, articles or criticism, is definitely shaped toward the promotion and fixation of mental and emotional patterns which predispose the reader to an acceptance of the advertiser's doctrinal message.

This secondary causal chain therefore runs as follows: Mass advertising entails the perversion of the editor-reader relationship; it entails reader-exploitation, cultural malnutrition and stultification.

This situation came to fruition during the period just before, during and after the war; a period of rapid technical, economic and social change culminating in the depression of 1929. At precisely the moment in our history when we needed a maximum of open-minded mobility in public opinion, we found a maximum of inertia embodied in our instruments of social communication. Since these have become advertising businesses, and competition is the life of advertising, they have a vested interest in maintaining and promoting the competitive acquisitive economy and the competitive acquisitive social psychol- 
ogy. Both are essential to advertising, but both are becoming obsolete in the modern world. In contemporary sociological writing we find only vague and passing reference to this crucial fact, which is of incalculable influence in determining the present and future movement of social forces in America.

In later chapters the writer will be found dealing coincidentally with advertising, propaganda and education. Contemporary liberal criticism tends to regard these as separate categories, to be separately studied and evaluated. But in the realm of contemporary fact, no such separation exists. All three are instruments of rule. Our ruling class, representing the vested interests of business and finance, has primary access to and control over all these instruments. One supplements the other and they are frequently used coordinately. Liberal sociologists would attempt to set up the concept of education, defined as a disinterested objective effort to release capacity, as a contrasting opposite to propaganda and advertising. In practice no such clear apposition obtains, or can obtain, as is in fact acknowledged by some of our most distinguished contemporary educators.

There is nothing unique, isolate or adventitious about the contemporary phenomena of advertising. Your ad-man is merely the particular kind of eccentric cog which the machinery of a competitive acquisitive society required at a particular moment of its evolution. He is, on the average, much more intelligent than the average business man, much more sophisticated, even much more socially minded. But in moving day after day the little cams and gears that he has to move, he inevitably empties himself of human qualities. His daily traffic in half-truths and outright deceptions is subtly and cumulatively degrading. No man can give his days to barbarous frivolity and live. And ad-men don't live. They become dull, resigned, hopeless. Or they become dæmonic fantasts and sadists. They are, in a sense, the intellectuals, the male hetæræ of our American commercial culture. Merciful nature makes some of them into hale, pink-fleshed, speech-making morons. Others become gray-faced cynics and are burned out at forty. Some "unlearn hope" and jump out of high windows. Others become extreme political and social radicals, either secretly while they are in the business, or openly, after they have left it.

This, then, is the advertising business. The present volume is merely a reconnaissance study. In addition to what is indicated by the foregoing, some technical material is included on the organization and practices of the various branches of the business. Some attempt is made to answer the questions: how did it happen that America offered a uniquely favorable culture-bed for the development of the phenomena described? What are the foreign equivalents 
of our American rule-by-advertising? How will advertising be affected by the present trend toward state capitalism, organized in the corporative forms of fascism, and how will the social inertias nourished and defended by advertising condition that trend?

The writer also attempts tentative measurements of the mental levels of various sections of the American population, using the criteria provided by our mass and class publications. Advertising men are obliged to make such measurements as a part of their business; they are frequently wrong, but since their conclusions are the basis of more or less successful business practice they are worthy of consideration.

The one conclusion which the writer offers in all seriousness is that the advertising business is in fact the Business Nobody Knows. The trails marked out in this volume are brief and crude. It is hoped that some of our contemporary sociologists may be tempted to clear them a little further. Although, of course, there is always the chance that the swift movement of events may eliminate or rather transform that particular social dilemma, making all such studies academic, even archaic. In that case it might happen that ad-men would be preserved chiefly as museum specimens, to an appreciation of which this book might then serve as a moderately useful guide.

Advertising has, of course, a very ancient history. But since the modern American phenomenon represents not merely a change in degree but a change in kind, the chronological tracing of its evolution would be only confusing. It has seemed better first to survey the contemporary phenomena in their totality and then present in a later chapter the limited amount of historical data that seemed necessary and pertinent. 


\section{THE APPARATUS OF ADVERTISING}

When we come to describe and measure the apparatus of advertising, some more or less arbitrary breakdown is necessary. Let us therefore start with the advertising agency, which is the hub of the advertising business proper, where all the lines converge. We shall then draw concentric circles, representing increasingly remote but genuinely related institutions, people and activities.

In Advertising Agency Compensation Professor James A. Young, of the University of Chicago, estimates that in 1932 there were 2,000 recognized national and local advertising agencies engaged in the preparation and placing of newspaper, magazine, direct-by-mail, carcard, poster, radio and all miscellaneous advertising. ${ }^{1}$ These 2,000 agencies served 16,573 advertisers. Advertisers served by agencies having recognition by individual publishers only are excluded from this estimate.

Prof. Young estimates the 1930 volume of advertising placed through 440 recognized agencies at $\$ 600,000,000$. An additional 370 agencies placed $\$ 37,000,000$ in that year. The trend during the postwar decade was steadily toward the concentration of the business in the larger agencies with a further concentration brought about by mergers of some of these already large units.

In 1930 there were six agencies doing an annual business of $\$ 20,000,000$ or over, and fourteen with an annual volume of from $\$ 5,000,000$ to $\$ 20,000,000$. A further indication of the trend is contained in the figures showing the advertising income of American Magazine, Colliers, Saturday Evening Post, Delineator, Good Housekeeping, Ladies' Home Journal, McCalls and Woman's Home Companion. In 1922, 57.8 per cent of the combined advertising income of these publications came from the ten leading agencies. In 1931 this proportion had risen to 68.3 per cent.

A similar trend toward concentration in the sources of advertising revenue is apparent. Advertisers spending between $\$ 10,000$ and $\$ 100,000$ annually dropped from 43.8 per cent of the total volume in 1921 to 21.1 per cent of the total volume in 1930. Advertisers spend- doi I original pdf

\footnotetext{
${ }^{1}$ [James A. Young, Advertising Agency Compensation in Relation to the Total Cost of Advertising (Chicago: University of Chicago Press, 1933).]
} 
ing between $\$ 100,000$ and $\$ 1,000$, 000 annually increased from 51.3 per cent of the total volume in 1921 to 55.9 per cent in 1930. Finally, advertisers spending over a million a year increased their percentage of the total volume from 4.9 per cent in 1921 to 23 per cent in 1930.

The agency employee, whether he writes advertising copy, draws advertising pictures or is concerned with one of many routine, mechanical and clerical processes of the agency traffic, must be listed as an advertising person; he makes his living directly out of the advertising business.

The manufacturer's or merchant's advertising staff is also clearly to be listed as a part of the personnel of the advertising business.

A publisher's representative, or "space salesman", is also clearly an advertising man; so is the circulation promotion manager and his staff-his budget is an advertising budget. But how about the editorial department of the newspaper or magazine? Here we are on debatable ground. If the newspaper or magazine is primarily an advertising business, since most of its income is derived from advertisers, and all of its activities, editorial and otherwise, are finally evaluated according to the degree of their utility in making the publication an effective and profitable advertising medium, then the total staff of the publication is an advertising staff; they too make their livings out of the advertising business.

Without attempting to settle the question, let us first consider certain statistical trends which show clearly enough the progressive transformation of our daily and periodical press into advertising businesses.

In 1909, 63 per cent of newspaper income and 51.6 per cent of magazine income was from advertising. By 1929 the proportion of advertising income had moved sharply upward to 74.1 per cent for newspapers and 63.4 per cent for periodicals. Approximately threequarters of the newspaper's dollar and two-thirds of the periodical's dollar came from advertisers.

To correspond with this trend we should expect to find a certain re-orientation of the function of the newspaper and periodical press, and that is precisely what we do find. The reader is asked to follow a digression at this point, since it is important to the general argument.

Increasingly over the past thirty years we find the newspaper asserting its freedom-in political terms. Coincidentally, of course, it has come more and more under the hegemony of business exercised through advertising contracts to be either given or withheld. In 1900, 732 dailies acknowledged themselves to be "democratic" and 801, "republican." By 1930, papers labeled "independent democrat" and "independent republican" had increased fivefold, while papers pretending to be "independent" politically jumped from 377 in 1900 to 
792 in 1930, when such papers constituted the largest single category. In commenting on this trend Messrs. Willey and Rice remark, in Recent Social Trends:

This increase in claimed political independence may indicate that the newspaper is becoming less important as an adjunct of the political party, that it seeks greater editorial freedom, or that it desires to include various political adherents within its circulation and advertising clientele. ${ }^{2}$

The italics are the writer's. What this statistical trend would appear to show, especially when coupled with the coordinate increase of the newspaper's dependence upon advertising income, is that the newspapers have realistically adapted themselves to the exigencies of a changing social and economic situation. This holds almost equally true of the periodicals. Politics as a means of government was definitely recessive during this period, and public interest in politics correspondingly declined. The powers of government were shifting to business. Hence the press became more and more "free." It freed itself from involvement with the nominal rulers, the political parties, in order that it might be free to court the patronage of the real rulers, the vested interests of business, industry, finance; in return for this patronage, the press became increasingly an instrument of rule operated in behalf of business. The press, being itself a profit-motivated business was in fact obliged to achieve this transition; to orient itself to the emerging focus of power, and to become in fact though not in name, an advertising business. In essence, what happened was that both major political parties had become, in respect to the class interests which they represented, one party, the party of business; the press, as an advertising medium, tended to represent that party.

Taking 1909 to 1929 as representing the crucial period of this transition we find that in 1909 the volume of newspaper advertising was $\$ 149,000,000$ and of periodical advertising $\$ 54,000,000$. By 1929 the figures were $\$ 792,000$, ooo for newspaper advertising and $\$ 320,000$, o00 for periodical advertising. Except for the movies, the automobile, and the radio, no other major American industry has rivaled the swift expansion of the advertising business.

We have then a combined total of $\$ 1,112,000,000$ as the contribution of newspaper and magazine advertisers to the advertising "pot." In computing the total contents of this pot we must duly add at least $\$ 75,000$,ooo for time on the air bought by advertisers from commercial broadcasters. The radio, since all its income is derived from advertisers, must be rated as essentially an advertising business. We must add $\$ 400,000,000$ for direct-by-mail advertising, $\$ 75,000$, ooo for outdoor advertising, $\$ 20,000,000$ for street-car advertising, \$75,000,000 for business papers, and $\$ 25,000,000$ for premiums, programs, directories, etc. The foregoing are 1927 figures cited by Copeland in
${ }^{2}$ [Malcolm M. Willey and Stuart A. Rice, "The Agencies of Communication," in Recent Social Trends, vol. 1 (New York: McGraw-Hill, 1933), 205.] 
Recent Economic Changes. 3 Advertising volume in all categories went up in 1928 and 1929 and radio volume continued to go up during the first three years of the depression. Also in these figures no allowance is made for radio talent bought and paid for by the advertiser, and none for art and mechanical costs of printed advertising, billed by the agency to the advertiser with a 15-per-cent commission added. Hence Copeland's grand total of $\$ 1,782,000,000$ for all advertising must be taken as a very conservative estimate of the peak volume of the business. Two billion would probably be closer. As to the number of workers engaged in the various branches of the business, detailed estimates are difficult to get, chiefly because of the confusion of categories.

The General Report on Occupations of the 15th Census gives figures of 5,453 men and 400 women as the personnel of advertising agencies, but under Advertising Agents and Other Pursuits in the Trade the figures are 43,364 men and 5,656 women. Printing, publishing and engraving must be considered as in large part services of supply for the advertising business as above defined, and the personnel of these trades, including printers, compositors, linotypers, typesetters, electrotypers, stereotypers, lithographers and engravers totals 269,030 men and 33,333 women. In 1927 printing, publishing and allied industries ranked as the fifth industry in the United States with a total volume of $\$ 2,094,000,000$.

The question, who is or is not connected with the advertising business is indeed baffling. Is the printer, who makes all or most of his living out of the advertising business, an advertising man? How about the engraver, the lithographer, the matmaker, the makers and sellers of paper and ink-all the hordes of people who as producers, service technicians, salesmen, clerks operate back of the lines as advertising's Service of Supplies? Many of these people, especially the salesmen, certainly think of themselves as advertising people. They are members in good standing of Advertising Clubs. Toss a chocolate eclair into the air at any Thursday noon luncheon of the Advertising Club of Kenosha, Wisconsin, or Muncie, Indiana, and the chances are three to one it will land on a printer or on an engraver. They are there strictly on business, of course, and their dues are carried as part of the firm's overhead. But how they believe in advertising!

Spread the net a little more widely and all kinds of strange fish flop and writhe in the meshes of advertising. The Alumni Secretary of dear Old Siwash-is he an advertising man? No? Then why is he a member of the local advertising club? And how about the football squad, their trainer, coach, waterboy, cheer-leaders, etc. are they advertising men? Well, the team advertises the college, and, by general agreement, is maintained chiefly for that purpose. Why, then, isn't
${ }^{3}$ [Morris A. Copeland, "The National Income and its Distribution," in Recent Economic Changes in the United States, vol. 2 (New York: National Bureau of Economic Research, 1929).] 
the personnel involved an advertising personnel?

Then there are the advertising departments of our numerous university-sanctioned Schools of Business Administration. Are these fellows advertising men or educators? Dr. Abraham Flexner maintains that they are not educators, while practical agency heads insist with equal energy that they are not advertising men. But they can't belong to nobody and the writer's guess is that they must, however reluctantly, be categoried as part of the personnel of the advertising business.

Hastening back to firm ground, we can agree that advertising copy-writers employed by agencies or advertisers are unmistakably advertising men. So are the fellows who sell space in publications. But how about the staffs of the various institutes, bureaus, etc., such as Good Housekeeping Institute, whose job is to test and pass on the products and appliances advertised in the publication? The raison d'etre of such departments is that they nourish the confidence of the reader and thus increase the value of the publication to the advertiser. Are these fellows scientists, engineers or advertising men?

Without attempting to answer this embarrassing question, let us go across the hall or upstairs to the editorial department of a modern publication. The "travel editor" is busy computing the current and prospective lineage bought by various steamship and railroad lines. On the result of this computation will depend whether next month she will praise the joys of California's sun-kist climate or the more de luxe attractions of the Riviera. Is the young woman an editor, a literary person or an advertising woman?

The fiction editor has on his desk a very suitable manuscript. It has neither literary nor other distinction, but the subject matter and treatment are excellent from a pragmatic point of view. The story tells how a young man was nobody and got nowhere until he bought some well-tailored clothes; with the aid of these clothes and other items of conspicuous waste, he established his social status and shrewdly used his newly-won acquaintances to promote his business career. He ends up as partner in the firm where he was formerly a despised bookkeeper. Moral: it pays to wear smart clothes, even if you have to go in debt to buy them. The story is in effect an excellent institutional advertisement for the men's clothing industry, and will be so regarded by present and prospective clothing advertisers. Is its author a literary man or an advertising man? Is the editor who chose this story, for the reasons indicated above, an editor and critic or an advertising man? The story will be illustrated by an artist who specializes in his knowledge of styles in men's clothing. When he makes his illustrations he will have before him as "scrap" the latest catalogues of the clothing houses. Is he an artist, an illustrator or an 
advertising man?

It may seem unkind to press the point, but we have barely begun to list the peripheral personnel of the advertising business. The electrician who repairs the neon signs on Broadway-is he an electrician or an advertising man? The truck driver who delivers huge rolls of paper to the press rooms of the newspapers-where would he be, but for the advertising business that keeps those presses busy dirtying that paper? And the bargemen who floated that newsprint across the Hudson? And the train crew that freighted it down from Maine? And the loggers in the Maine woods that supply the pulp mills? And the writers for the "pulps" who go to Maine for their vacations?

It is not necessary to project this unbroken continuity into the realm of fantasy. Both in respect to the number of persons employed and the total value of manufactured products, advertising is, or was in 1929, one of the twelve major industries of the country. We are living in a fantastic ad-man's civilization, quite as truly as we are living in what historians are pleased to call a machine age, and a very cursory examination of the underlying economic trends will be sufficient to show how we got there.

The essential dynamic of course is the emergence of our "surplus economy" predicament, generated by the application of our highly developed technology to production for profit. Advertising played a more or less functional though barbaric and wasteful role during the whole expansionist era of American capitalism. The obsolescence, the reductio ad absurdum of advertising is betrayed by the exaggerations, the grotesqueries, which accompanied its period of greatest expansion during the postwar decade. Like many another social institution, it flowered most impressively at the very moment when its roots had been cut by the shift of the underlying economic forces.

Between 1870 and 1930 several millions of people were squeezed out of production. Where did they go? The statistical evidence is plain. In 1870 about 75 per cent of the gainfully employed people of the United States were engaged in the production of physical goods in agriculture, mining, manufacture and construction. In 1930 only about 50 per cent of the labor supply was so required. In 1870 , ten per cent of the employed population was engaged in transportation and distribution. In 1930, 20 per cent was engaged in transportation and distribution. What caused this shift was chiefly the increase in man-hour productivity made possible by improvements in machine technology and in the technique of management. The chapter on "Trends in Economic Organization" by Edwin F. Gay and Leo Wolman in Recent Social Trends documents this increase as follows:

The combined physical production of agriculture and of the manufacturing, mining and construction industries increased 34 per cent 
from 1922 to $1929 \ldots$... The advance in output was steady throughout the period and even in the recession years, 1924 and 1927, the decline was surprisingly small. Much more important, however, is the comparison between the rate of increase in physical output in the prewar and postwar periods. Per capita output, reflecting retardation in the rate of population growth, as well as the rise in production, advanced twice as fast in the later years as in the earlier, as is indicated by the average annual rate of increase. 4

$\begin{array}{lccc}\text { Period } & \begin{array}{c}\text { Volume of } \\ \text { production } \\ \text { percent }\end{array} & \begin{array}{c}\text { Population } \\ \text { per cent }\end{array} & \begin{array}{c}\text { Per capita } \\ \text { production }\end{array} \\ & +3.1 & & \text { per cent } \\ 1901-1913 & +3.8 & +2.1 & +1.1 \\ 1922-1929 & +1.4 & +2.4\end{array}$

Although real wage levels rose slightly during this period they did not rise proportionately to the increase in man-hour productivity, the increase in profits, the increase in plant investment, and the increase in capital claims upon the product of industry. The result of these conflicting trends was to place an increasing burden upon the machinery of selling. This is reflected in the rising curve of sales overhead, the increase in small loan credit and installment selling and the meteoric rise of advertising expenditure during the post-war period. According to the estimate of Robert Lynd in Recent Social Trends the total volume of retail installment sales in 1910 was probably under a billion dollars. By 1929 it had increased to seven billion dollars. 5

Undoubtedly this six-billion-dollar shot in the arm postponed the crisis, intensified its severity and contributed importantly to the Happy Days of advertising during the New Era. After the crash it was of course the ad-men who were urged to put Humpty-Dumpty back on the wall. They tried manfully, but since it is impossible to advertise a defunct buying power back into existence, they didn't succeed. And now, after four years of depression it would appear that the ad-man has learned nothing and forgotten nothing.

That two-billion-dollar advertising budget is a lot of money. In 1929 it represented about two per cent of the national income for that year, or \$15 per capita. It might well be alleged that the bill was high, would have been high even for a competently administered service of information. And, as already indicated, advertising is scarcely that. What that two billion represented, what the present billion and a half advertising volume represents, is in considerable part the tax which business levies on the consumer to support the machinery of its super-government-the daily and periodical press, the radio, the apparatus of advertising as we have described it. By this super-
${ }^{4}$ [Edwin F. Gay and Leo Wolfman, "The Agencies of Communication," in Recent Social Trends, vol. 1 (York, PA: Maple Press Company, 1933), 232.]

\footnotetext{
${ }^{5}$ [Robert S. Lynd, "The People as Consumers," in Recent Social Trends, vol. 2 (York, PA: Maple Press Company, 1933).]
} 
government the economic, social, ethical and cultural patterns of the population are shaped and controlled into serviceable conformity to the profit motivated interests of business.

Our notoriously extravagant official government is really much more modest, considering that it gives us in return such tangible values as roads, sewers, water, schools, police and fire departments, and such grandiose luxuries as the army and navy. The combined tax bill of the nation, Federal, State, and local, amounted to only $\$ 10,077,000,000$ in 1930 or roughly about $\$ 75$ per capita.

It will be argued, of course, that even if advertising is thrown out of court as a service of information, since that is neither its intent nor its effect, nevertheless this two-billion dollar industry does net us something. But for advertising, we should not be able to enjoy the radio free, or read the Saturday Evening Post at five cents a copy, or Mr. Hearst's American Weekly, which is thrown in free with his Sunday newspapers. In other words, it will be argued that advertising is justifiable as an indirect subsidy of our daily and periodical press and the radio; that for this two billion dollars, which has to be charged ultimately to the consumer, we get a tremendous quantity of news, information, criticism, culture, pretty pictures, education and entertainment. We do, indeed, and as taxpayers we value this contribution to our welfare so highly that our Post Office Department also heavily subsidizes our daily and periodical press. Also we pay the Federal Radio Commission's annual million-dollar budget, consumed chiefly in adjusting commercial dog-fights over wave lengths.

But the actual quality and usefulness of what we get is another matter. In exchange for these official and unofficial subsidies we get a daily and periodical press which has practically ceased to function as a creative instrument of democratic government: which does, however, function effectively as an instrument of obscuration, suppression and cultural stultification, used by business in behalf of business; which levels all cultural values to the common denominator of emulative acquisition and social snobbism, which draws its daily and weekly millions to feast on the still-born work of hamstrung reporters, escape-formula fictioneers, and slick-empty artists; which, having stupefied its readers with this sour-sweet stew of nothingness, can be counted on to be faithful to them in all issues which don't particularly matter and to betray them systematically and thoroughly whenever their interests run counter to the vested interests of business.

In this indictment it is not denied that we have in America many honest newspapers and honest magazines, honest editors, honest reporters and honest advertising men. They are honest and blameless within the limits of the pattern prescribed for them by the economic 
determinants of the institutions which they serve. Some of them even struggle at great peril and sacrifice to break through and transcend these limits. It is inevitable that they should do so, since not only their readers but themselves are violated by the compulsions of the system in which both are caught.

But the system itself is substantially as described. The American apparatus of advertising is something unique in history and unique in the modern world; unique, fantastic and fragile. One needs but little knowledge of history, or of the movement of contemporary economic and social forces, to know that it can't last. It is like a grotesque, smirking gargoyle set at the very top of America's skyscraping adventure in acquisition ad infinitum. The tower is tottering, but it probably will be some time before it falls. And so long as the tower stands the gargoyle will remain there to mock us.

The gargoyle's mouth is a loud speaker, powered by the vested interest of a two-billion-dollar industry, and back of that the vested interests of business as a whole, of industry, of finance. It is never silent, it drowns out all other voices, and it suffers no rebuke, for is it not the Voice of America? That is its claim and to a degree it is a just claim. For at least two generations of Americans-the generations that grew up during the war and after-have listened to that voice as to an oracle. It has taught them how to live, what things to be afraid of, what to be proud of, how to be beautiful, how to be loved, how to be envied, how to be successful. In the most tactful manner, and without offending either the law or the moralities, it has discussed the most intimate facts of life. It has counselled with equal gravity the virtue of thrift and the virtue of spending. It has uttered the most beautiful sentiments concerning the American Home, the Glory of Motherhood, the little rosebud fingers that clutch at our heartstrings, the many things that must be done, and the many, many things that must be bought, so that the little ones may have their chance. It has spoken, too, of the mystery of death, and the conspicuous reverence to be duly bought and paid for when Father passes away.

So that today, when one hears a good American speak, it is almost like listening to the Oracle herself. One hears the same rasping, over-amplified, whisky-contralto voice, expressing the same ideas, declaring allegiance to the same values.

So that when somebody like the writer rises to say that the Oracle is a cheat and a lie: that he himself was the oracle, for it was he who cooed and cajoled and bellowed into the microphone off stage; that he did it for money and that all the other priests of the Advertising Oracle were and are similarly motivated: that the Gargoyle-oracle never under any circumstances tells the truth, the whole truth and nothing but the truth, for the truth is not in her: that she corrupts 
everything she touches—art, letters, science, workmanship, love, honor, manhood....

Why, then, your American is not in the least abashed. He knows the answer. It was pretty smart, wasn't it? It certainly does pay to advertise! You know, I've always thought I'd like to write advertisements! How does one get into the Advertising Business? 